\title{
Biología molecular del carcinoma de células claras renales: Principios para un tratamiento selectivo
}

\author{
Grande Pulido E*, Martín Centeno A*, Maroto Rey P**, Solsona Narbón E***. \\ *Departamento Médico de Pfizer, **Servicio de Oncología Médica Hospital Santa Creu i Sant Pau de Barcelona. \\ ***Servicio de Urología. Instituto Valenciano de Oncología.
}

Actas Urol Esp. 2007: 31(3);233-243

\section{RESUMEN}

BIOLOGÍA MOLECULAR DEL CARCINOMA DE CÉLULAS CLARAS RENALES: PRINCIPIOS PARA UN TRATAMIENTO SELECTIVO

El cáncer de células renales (CCR) y más concretamente el subtipo más frecuente de células claras, se he mostrado resistente al tratamiento con quimioterapia y radioterapia cuando afecta a pacientes con metástasis a distancia. En los últimos años se han realizado grandes avances en el campo de la biología molecular que origina este tipo de tumores. Esto ha conducido a un mejor conocimiento del origen de la enfermedad y ha permitido el desarrollo de nuevos fármacos que actúan sobre los factores de crecimiento implicados en el desarrollo del tumor. En este artículo de revisión se resumen de manera concisa los hitos a nivel molecular que originan el desarrollo de los tumores renales de células claras.

Palabras Clave: Biología molecular. Cáncer. Renal. VHL. VEGF.

\section{ABSTRACT \\ MOLECULAR BIOLOGY OF THE CLEAR CELL RENAL CELL CARCINOMA: PRINCIPLES FOR A SELECTIVE TREATMENT}

Renal cell carcinoma (RCC) and its most frequent subtype, the clear cell hystology type, has shown resistance to chemotherapy and radiotherapy treatment when disease was already spread in patients. Recently, a huge advance in the molecular biology of this tumor has been performed. This fact allowed a deeper and better knowledge of the disease and the development of new drugs that work against the growth factors involved in tumor origin. In this review article it is summarized the molecular milestones that are involved in the development of clear cell renal cell carcinomas.

Keywords: Molecular biology. Cancer. Renal. VHL. VEGF.

S estima que aproximadamente 40.000 nuevos casos de cáncer de células renales (CCR) se diagnostican cada año en Europa, los cuales son responsables de unas 20.000 muertes al año ${ }^{1}$. El $\mathrm{CCR}$, en términos generales, supone alrededor del $2 \%$ del total de los tumores diagnosticados en el adulto $^{2}$. Un tercio de los pacientes se diagnostica ya en una etapa avanzada de la enfermedad, con la presencia de metástasis a distancia ${ }^{3}$. El CCR se ha considerado clásicamente resistente al tratamiento con quimioterapia ${ }^{4}$.
El CCR cuenta con varios subtipos histológicos, cada uno de los cuales deriva de las distintas áreas del epitelio renal. Los tumores epiteliales renales más comúnmente encontrados son; carcinoma de células claras renales $(75 \%)$, carcinoma papilar renal (15\%), los tumores cromófobos (5\%) y los oncocitomas $(5 \%)^{5}$.

El CCR se produce a consecuencia de la adquisición de distintas propiedades por el tumor siguiendo el modelo de carcinogénesis con sucesivos "pasos". A lo largo de estas sucesivas etapas, 
el CCR adquiere progresivamente "atributos" que le permiten resistir a señales inhibitorias de crecimiento exógenas, evadir la apoptosis, perder la capacidad del control del ciclo celular con lo que la célula prolifera sin límites, desarrollarse a pesar de un microambiente pobre en oxígeno, crear inmunotolerancia en el huésped en el que asientan, generar factores angiogénicos, invadir la membrana basal y por último, metastatizar a distancia ${ }^{6,7}$.

Tanto las formas esporádicas como las hereditarias de carcinoma renal de células claras se asocian a mutaciones en el gen del von Hippel Lindau (VHL). En concreto, prácticamente la totalidad de los CCR de células claras que asientan en el seno de un síndrome de VHL y el 60-80\% de los CCR esporádicos se asocian a mutaciones del gen de VHL. Este tipo de tumores se caracterizan por presentar una profusa vascularización y derivar de las células epiteliales renales originadas en los túbulos contorneados proximales de las nefronas. Uno de los eventos más precoces que ocurren en la carcinogénesis de los CCR de células claras es una mutación que ocasiona pérdida de función en el gen del $\mathrm{VHL}^{8}$. El funcionamiento aberrante del gen del VHL se traduce en la liberación de una serie de factores de crecimiento tales como el factor de crecimiento vascular endotelial (VEGF), el factor de crecimiento derivado de plaquetas (PDGF) o el factor de crecimiento transformante alfa (TGF- $\alpha$ ), entre otros, implicados en el crecimiento y proliferación de la propia célula tumoral así como en el proceso de angiogénesis necesario para mantener el aporte de oxígeno y nutrientes que asegure la viabilidad y desarrollo tumoral $^{9}$.

Un mejor conocimiento de la biología molecular de estos CCR de células claras ha permitido identificar dianas específicas derivadas del proceso de carcinogénesis sobre las que podemos actuar. De este modo surge el término de terapia molecular dirigida que rápidamente se ha incorporado al tratamiento de éste y otros tumores tales como el tumor del estroma gastrointestinal, la leucemia mieloide crónica o el cáncer de colon entre otros.

\section{SÍNDROMES HEREDITARIOS ASOCIADOS AL CÁNCER RENAL}

El síndrome hereditario que más frecuentemente se asocia con el desarrollo de CCR de célu- las claras es el propio síndrome de von HippelLindau. Este síndrome fue descrito por primera vez en la literatura hace más de 100 años ${ }^{10-12}$. Como la mayoría de los síndromes hereditarios asociados a cáncer, esta enfermedad se produce a consecuencia de mutaciones germinales en un gen, en este caso el VHL. VHL es un gen cuya actividad en la célula normal es la inhibición de determinadas funciones. El sindrome de VHL se caracteriza por la formación de tumores derivados de vasos sanguíneos, denominados hemangioblastomas, que se localizan principalmente en la retina (presentes en el 70\% de los pacientes) y en el sistema nervioso central (presentes en el $84 \%$ de los pacientes). Los tumores que se producen en el sistema nervioso central se localizan con mayor frecuencia en el cerebelo y médula espinal. Otros tumores asociados al síndrome de VHL son CCR de células claras (aparecen en el $69 \%$ de los pacientes), feocromocitomas, tumores del saco endolinfático, tumores derivados de las células de los islotes pancreáticos y cistoadenomas papilares del epidídimo en hombres o del ligamento ancho en las mujeres ${ }^{13}$. La prevalencia de la enfermedad de VHL es de aproximadamente 1 de cada 100.000 individuos $^{14,15}$. La edad a la que se desarrollan signos y sintomas suele ser a partir de los 30 años, principalmente derivados de los hemangioblastomas y de los CCR de células claras ${ }^{15}$. Un $20-30 \%$ de los pacientes fallecen a causa de un carcinoma renal, generalmente por debajo de los 50 años ${ }^{16}$.

Se han descrito hasta 10 sindromes hereditarios asociados al CCR que se describen en la Tabla $1^{17}$. Dentro de estas enfermedades hereditarias destaca el síndrome de Birt-Hogg-Dubé (BHD) que es una genodermatosis de transmisión autosómica dominante caracterizada por erupciones cutáneas prominentes, neumotórax espontáneos asociados con quistes en el parénquima pulmonar y una alta predisposición a padecer tumores renales de tipo cromófobo, oncocitomas y mixtos. Las lesiones cutáneas son características, se denominan fibrofoliculomas (hamartomas del folículo piloso) y consisten en múltiples pápulas indoloras de 2 a $3 \mathrm{~mm}$ de diámetro en la piel del territorio de la cabeza y el cuello en individuos mayores de 30 años. Se cree que este síndrome es debido a una mutación que origina una pérdida de función en 
Tabla 1

Sindromes hereditarios asociados con $\mathrm{CCR}^{17}$

\begin{tabular}{lll}
\hline Enfermedad & Tipo de CCR & Alteración genética \\
\hline $\begin{array}{l}\text { Síndrome de von Hippel-Lindau } \\
\text { Translocaciones del cromosoma } 3\end{array}$ & CCR de células claras bilaterales y múltiples & VHL (3p25-26) \\
CCR de células claras bilaterales y múltiples & $\begin{array}{l}\text { Desconocido, probable implicación } \\
\text { del VHL }\end{array}$ \\
$\begin{array}{l}\text { Paraganglioma hereditario } \\
\text { Tuberosis esclerosa }\end{array}$ & CCR de células claras & Desconocido \\
CCR papilar hereditario & CCR de células claras y angiomiolipomas & SDHB (1p36) \\
$\begin{array}{l}\text { Síndrome de Reed o de } \\
\text { leiomiomatosis uterina }\end{array}$ & CCR papilar bilateral y múltiple & TSC2 (16p13) \\
Síndrome hiperparatiroideo & CCR papilar solitario y unilateral & MET (7q31) \\
Cáncer de tiroides familiar papilar & CCR papilar y oncocitomas & FH (1q42-43) \\
Síndrome de Birt-Hogg-Dube & CCR de células claras, oncocitoma, cromófobos & DHD (17p11) \\
\hline
\end{tabular}

el gen BHD, localizado en el cromosoma $17 \mathrm{p}^{18-20}$. $\mathrm{El}$ gen $\mathrm{BHD}$ es un gen supresor que codifica para una proteína denominada foliculina ${ }^{21}$. Mutaciones en el gen BHD se evidencian raramente en los CCR esporádicos ${ }^{22}$. Sin embargo, en los casos de pacientes con síndrome de BHD y tumores cromófobos $\mathrm{u}$ oncocitomas renales, se encuentran altas tasas de mutaciones en este gen ${ }^{23}$.

El Síndrome de Reed, también conocido como síndrome de leiomiomatosis uterina y cutánea, se caracteriza por la presencia de leiomiomas cutáneos, fibromas uterinos y CCR que pueden ser únicos o múltiples y bilaterales ${ }^{24}$. Estos tumores renales que asientan en el síndrome de Reed son de naturaleza muy agresiva y suelen causar la muerte del paciente a los 30 años. Este síndrome se produce a consecuencia de una mutación en el gen de la fumarato hidratasa $(\mathrm{FH})^{25,26}$. El gen de la FH codifica para un enzima del ciclo de Krebs llamada fumarato hidratasa. Se han descrito unas 40 mutaciones a lo largo de todo el gen de la $\mathrm{FH}$, localizado en el cromosoma 1 , sin que se haya evidenciado hasta la fecha una clara relación genotipo-fenotipo ${ }^{17}$.

El CCR papilar hereditario es una enfermedad autosómica dominante asociada al desarrollo de múltiples y bilaterales CCR papilares multifoca$\operatorname{les}^{23}$. Se ha asociado con mutaciones en el oncogen c-MET del cromosoma 7, que codifica para el receptor del factor de crecimiento de los hepato- citos $^{27-29}$. En estos tumores hereditarios se produce una mutación en el proto-oncogen MET que se traduce en una activación anómala del dominio tirosina kinasa del receptor del factor de crecimiento de los hepatocitos, quedando éste activado intrínsecamente independientemente de la unión o o no de su ligando. Esto conlleva una transformación celular que hace perder el control de la proliferación ${ }^{23}$. Estos tumores papilares habitualmente se diagnostican a los 70 años y generalmente no se asocian a metástasis.

Como se puede apreciar, cada sindrome familiar se asocia a un tipo histológico definido y hay una clara asociación genotipo-fenotipo. Todos ellos presentan herencia autosómica dominante y la mayoría de ellos presentan otras manifestaciones clínicas además de los tumores renales. Se debe sospechar que nos encontramos ante un caso de cáncer renal hereditario cuando al diagnóstico un paciente presente un CCR bilateral o múltiple, o a una edad temprana. El diagnóstico se debe realizar mediante el análisis genómico de los principales genes implicados (VHL, MET, FH y $\mathrm{BDH})^{30-32}$.

\section{ANATOMÍA DEL GEN DEL VHL}

El gen VHL se localiza en el cromosoma 3 (3p25-26) ${ }^{33}$. Este gen contiene 3 exones y codifica para un ARN mensajero de aproximadamente $4,5 \mathrm{~kb}$ con una extensa región 3' no traduci- 
$\mathrm{da}^{34,35}$. El promotor de VHL contiene lugares de unión para múltiple factores de transcripción tales como Sp1, AP-2, PAX y el factor nuclear respiratorio- $1^{36}$. Se han identificado genes homólogos al VHL humano en ratones, ratas, gusanos y en la mosca de la fruta ${ }^{37-40}$.

La proteína codificada por el gen del VHL (pVHL) consta de 213 residuos de aminoácidos y tiene un peso molecular estimado entre 24 y 30 $\mathrm{kDa}^{41}$. Existe una segunda isoforma de la $\mathrm{pVHL}$ que se produce en algunas células a raíz de un inicio de la transducción interna desde la secuencia ATG del codón 54, presentando un peso molecular menor que oscila entre 18 y 20 $\mathrm{kDa}^{42-44}$. Ambas isoformas se comportan de manera muy similar en los ensayos realizados hasta la fecha por lo que no se suelen hacer distinciones entre ambas cuando se habla del derivado proteico del gen VHL. La pVHL se localiza principalmente en el citoplasma aunque ocasionalmente se puede observar también en el núcleo ${ }^{45}$.

\section{COMPLEJO PROTEICO DEL VHL Y EL FACTOR INDUCIBLE POR HIPOXIA}

La pVHL no actúa por sí misma en la célula, sino que requiere unirse a otras proteínas plasmáticas para realizar su función, formando un complejo proteico. Diversos estudios llevados a cabo a mediados de los 90s demostraron que la pVHL se unía a otras dos proteínas denominadas elonguina $\mathrm{B}$ y elonguina $\mathrm{C}^{46,47}$ Estas dos proteínas, cuando se unen a la elonguina $\mathrm{A}$, forman un complejo de elongación transcripcional denominado elonguina o $\mathrm{SIII}^{48}$. La pVHL, al menos in vitro, compite con la elonguina A para unirse a las elonguinas $\mathrm{B}$ y $\mathrm{C}$, por lo que inhibe la actividad de la elonguina/SIII ${ }^{49}$. La región de la pVHL que se une a la elonguina $\mathrm{B}$ y $\mathrm{C}$ se encuentra frecuentemente mutada en la enfermedad de von Hippel Lindau ${ }^{49,50}$. Aunque podría parecer que la elonguina A y la pVHL compiten entre sí en la célula por unirse a las elonguinas $\mathrm{B}$ y $\mathrm{C}$, se ha comprobado que la concentración de ambas elonguinas in vivo excede la necesaria para que no exista competencia como tal ${ }^{51}$.

Cuando la pVHL se une a las elonguinas B y $\mathrm{C}$ forman un complejo que a su vez se une a una cuarta proteína denominada Cul2 ${ }^{13,52}$. La proteí- na Cul2 pertenece a la familia de las culinas que son las encargadas de la ubiquitinización de otras proteínas necesaria como paso previo a la degradación de éstas por el proteosoma ${ }^{53}$. Por último, el complejo pVHL/elonginaBC/Cul2 interactúa con una última proteína que es la $\mathrm{Rbx} 1$ (también llamada Hrt1 o ROC1) (Fig. 1) que facilita el proceso de ubiquitinización ${ }^{54-57}$.

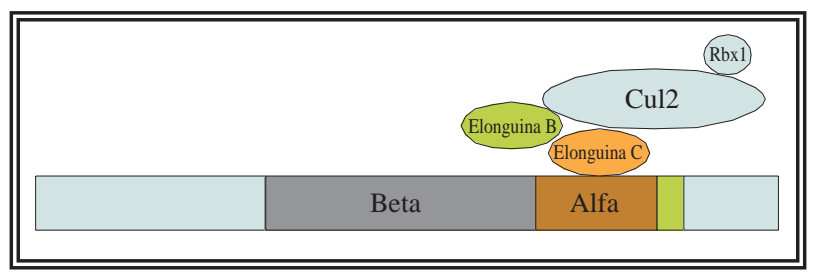

FIGURA 1. Complejo proteico del von Hippel-Lindau.

El complejo supresor tumoral del VHL se encarga de catalizar la reacción química de ubiquitinización del factor inducible por hipoxia alfa $($ HIF- $\alpha)$ para su posterior degradación por el proteosoma. El HIF- $\alpha$ se encuentra implicado en la formación de los factores de crecimiento relacionados con la angiogénesis y la proliferación celular como posteriormente se comentará.

La pVHL contiene dos subdominios denominados alfa y beta ${ }^{50}$. El subdominio alfa, que a su vez está formado por tres hélices alfa, se une directamente a la hélice alfa de la elonguina $\mathrm{C} \mathrm{y}$ genera un grupo de cuatro hélices alfa intermolecular. La elonguina B se une a la pVHL a través de la elonguina $\mathrm{C}$. El subdominio beta de la pVHL se une directamente al HIF- $\alpha$. Tanto el subdominio alfa como el beta son regiones donde asientan las mutaciones que con mayor frecuencia dan lugar a la enfermedad de von Hippel-Lindau. Estas mutaciones son de tipo silenciadoras y producen una disminución en la afinidad de la pVHL por el HIF ${ }^{58-60}$. A su vez, la pVHL se une a la región del HIF- $\alpha$ denominada dominio de degradación dependiente de oxígeno (ODD) (Fig. 2) ${ }^{58}$.

El HIF es el mediador clave de la hipoxia celular. Pertenece a una familia de factores de trasncripción denominada PAS (per/aryl-hydrocarbon-receptor nuclear translocator (ARNT)/Sim) ${ }^{61}$. El HIF se subdivide en dos subunidades, una se denomina alfa y su concentración en el citoplasma celular es oxígeno-dependiente, y la otra se denomina beta o subunidad ARNT y se encuentra 


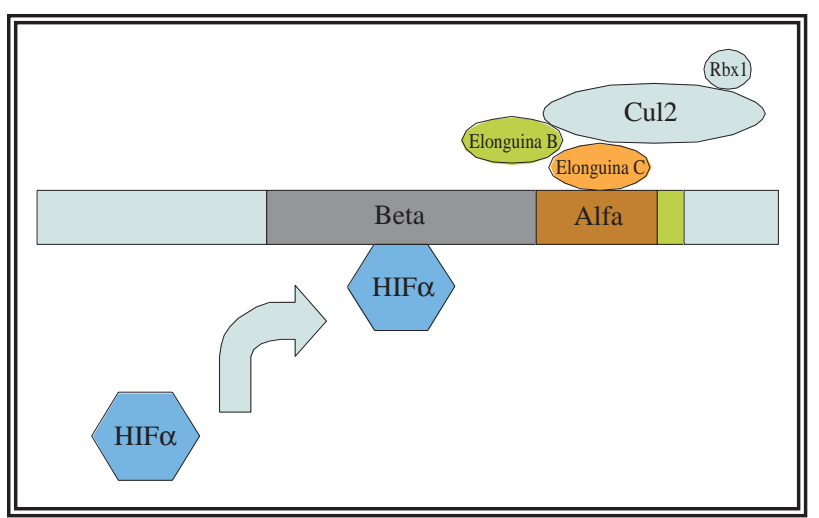

FIGURA 2. Complejo supresor tumoral del von HippelLindau unido al factor inducible por hipoxia alfa.

constitutivamente en el citoplasma independientemente de la concentración de oxígeno ${ }^{62}$. Estas dos subunidades de HIF son las responsables de la regulación de la homeostasis del oxígeno en la célula de tal manera que permiten a ésta adaptarse tanto a la presencia como a la deprivación de oxígeno a través de la regulación de la expresión de los distintos genes implicados en el metabolismo celular (GLUT-1), angiogénesis (VEGF, PDGF), eritropoyesis (eritropoyetina), apoptosis, proliferación celular (Bcl-2, p21 y p27) y otros procesos biológicos ${ }^{9}$. El heterodímero formado por las dos subunidades del HIF (alfa y beta) actúa como factor de transcripción de los distintos genes implicados en la hipoxia y actúan en respuesta a elementos sensibles a la falta de oxígeno. Dentro de los genes cuya regulación viene dada por el HIF se encuentran el gen que codifica para el factor de crecimiento vascular endotelial (VEGF), la hemo-oxigenasa-1, el activador del plasminógeno-1, el inhibidor tisular de metaloproteinasa- 1 o el factor de crecimiento del tejido conectivo $^{63}$.

La activación del HIF depende de la estabilización de la subunidad-alfa dependiente de oxígeno y su posterior translocación al núcleo donde forma un complejo funcional con la subunidad beta del HIF (ARNT) y otros coactivadores transcripcionales tales como CBP/p300 ${ }^{61,62}$. Normalmente, bajo condiciones de aporte adecuado de oxígeno, HIF- $\alpha$ se une al complejo proteico supresor del VHL que conduce a una reacción de ubiquitinización de del HIF- $\alpha$, que la señala para su posterior degradación por el proteosoma. Esta interacción se encuentra altamente conservada entre distintas especies y se basa en una hidroxilación de un residuo prolina y asparagina del HIF- $\alpha$ gracias a la HIF-prolil-hidrolasa.

\section{BIOLOGÍA MOLECULAR DEL CÁNCER RENAL DE CÉLULAS CLARAS Y SU ASOCIACIÓN CON EL VHL Y HIF}

Siguiendo el modelo de carcinogénesis clásico de "dos insultos" (two-hit model) de Knudson ${ }^{64}$, se requiere una mutación en la línea germinal en alguno de los dos alelos del gen del VHL heredada y además, se requiere una segunda mutación adquirida en el otro alelo para el desarrollo de un CCR de células claras en el seno de un síndrome de VHL. El síndrome de VHL es autosómico dominante, con un solo alelo afecto se padece el síndrome, lo que es necesario es un segundo insulto para desencadenar alguna de las manifestaciones fenotípicas del síndrome. Es necesaria la sucesión de alteraciones genéticas para que tengan lugar estos procesos patológicos ${ }^{65}$. Estudios de mutaciones en el gen del VHL en pacientes afectos del síndrome hereditario han demostrado que este gen es de tipo supresor tumoral y que las mutaciones que dan lugar al síndrome de VHL son de tipo silenciadoras, inhibiendo la función del gen ${ }^{66}$.

La etiopatogenia del CCR de células claras esporádico (no hereditario) es similar a la demostrada en el síndrome de VHL. Del mismo modo, el desarrollo de un CCR de células claras esporádico requiere al menos "dos golpeos", uno en cada alelo, que ocasionan mutaciones somáticas. Delecciones en alguno de los alelos del gen del VHL se han demostrado en el $84 \%$ de los $\mathrm{CCR}^{67-70}$. En la Tabla 2 se muestran las distintas alteraciones encontradas por diferentes autores en el gen del VHL ${ }^{65}$. En las series publicadas se han observado la presencia de mutaciones en el gen del VHL en el 34 al $57 \%$ de los CCR de células claras. La inactivación del gen del VHL también se puede producir debido a metilaciones en la porción del $\mathrm{ADN}$ rico en nucleósidos CpG que producen la incapacidad para transducir el gen. Aproximadamente en el 5 al $19 \%$ de estos CCR de células claras presentan metilaciones en el gen del $\mathrm{VHL}^{65}$. Teniendo en cuenta los datos de mutaciones y metilaciones en el gen del VHL, obtenemos que la inactivación bialélica del gen del VHL tiene lugar en la mayoría de los casos de CCR de células claras. 
Tabla 2.

Inactivación del gen del VHL en CCR de células claras en distintas series. Estraído de Rini et $\mathrm{al}^{65}$.

\begin{tabular}{|c|c|c|}
\hline Estudio & $\begin{array}{l}\text { Mutación en el gen del VHL } \\
\text { № de pacientes }\end{array}$ & $\%$ \\
\hline Gnarra $^{67}$ & $56 / 98$ & 57 \\
\hline Gallou $^{71}$ & $73 / 130$ & 56 \\
\hline Brauch $^{70}$ & $68 / 151$ & 45 \\
\hline Shuin $^{68}$ y Kondo 69 & $104 / 202$ & 51 \\
\hline Schrami $^{72}$ & $38 / 113$ & 34 \\
\hline \multirow[t]{2}{*}{ Total } & $339 / 694$ & 49 \\
\hline & \multicolumn{2}{|l|}{ Metilaciones en el gen del VHL } \\
\hline $\operatorname{Herman}^{73}$ & $5 / 26$ & 19 \\
\hline Clidfford ${ }^{74}$ & $7 / 45$ & 16 \\
\hline Kondo 69 & $11 / 202$ & 5 \\
\hline Brauch $^{70}$ & $110 / 151$ & 7 \\
\hline Total & $33 / 424$ & 8 \\
\hline
\end{tabular}

La frecuencia de inactivación del gen VHL es similar en tumores de pequeño tamaño y bajo grado histológico que en tumores de mayor tamaño y mayor agresividad histológica, lo que confirma nuevamente que la mutación en el gen es un evento muy precoz en el desarrollo del carcinoma de células claras ${ }^{69,70,72}$. La mayoría de las series mencionadas previamente describen el estado mutacional del gen VHL en el tumor primario exclusivamente, sin embargo en la serie de Herman et $\mathrm{al}^{73}$ se correlaciona la presencia de estas mutaciones en el tumor primario con las mutaciones y metilaciones encontradas en los ganglios linfáticos metastáticos de estos tumores. Los hallazgos encontrados en esta serie apoyan la naturaleza clonal de las anormalidades genéticas que asientan en el gen del VHL.

Cuando se analizaron CCR no-células claras no se evidenció una clara relación con el grado de inactivación del gen del VHL ${ }^{73-75}$. Las diferencias a nivel genético entre los CCR de células claras y los no-células claras se reflejan en las distintas formas histológicas y su diferente comportamiento e historia natural de los distintos tumores ${ }^{76,77}$. Cabe destacar que la mayoría de las mutaciones que se producen en el gen del VHL ocasionan una pérdida de heterocigosidad del gen que deriva en una proteína del VHL truncada que a su vez resulta en una pérdida de la función del gen que apoya la relevancia biológica que tiene la inactivación del gen del VHL en la carcinogénesis del CCR de células claras ${ }^{65,69,71,75}$.

Tal y como antes se ha comentado, la pVHL forma un complejo supresor tumoral al unirse a otras 4 proteínas; las elonguinas $\mathrm{C} \mathrm{y} \mathrm{B,} \mathrm{Cul2} \mathrm{y}$ Rbxl. Este complejo proteico del VHL interviene en la catalización del proceso de ubiquitinización por el cual se transfieren residuos de ubiquitinina que "marcan" distintas proteínas celulares para su degradación y eliminación a través del proteosoma $^{6}$. En concreto, al hablar del CCR de células claras, la función que desempeña el complejo supresor tumoral del VHL es la de ubiquitinizar el factor transcripcional HIF- $\alpha^{59}$. La función que desempeña de manera habitual en la célula el heterodímero del factor de transcrpción HIF formado por la unión de las subunidades $\alpha$ y $\beta$ es la de regular la expresión de los distintos genes implicados en la hipoxia celular atendiendo a las concentraciones de oxígeno que se encuentran presentes en la célula ${ }^{78}$.

Las células humanas responden a la hipoxia a través de diferentes vías, muchas de las cuales están a su vez mediadas por el factor de transcripción HIF. Bajo concentraciones de oxígeno suficientes (normoxia) se encuentra hidroxilado en dos residuos prolina y asparagina localizados en el "dominio de degradación dependiente de oxígeno" (ODD). Esta hidroxilación permite el reconocimiento por parte del complejo supresor tumoral del VHL del HIF- $\alpha$, que se ensamblan y se lleva a cabo la reacción de ubiquinización por el que se marca al factor de transcripción HIF- $\alpha$. A consecuencia de esta ubiquinización, el HIF- $\alpha$ será degradado por el proteosoma de la célula ${ }^{79}$ (Fig. 3).

En condiciones de hipoxia, al no existir suficiente concentración de oxígeno, el factor de transcripción HIF- $\alpha$ no se hidroxila, por lo que no es reconocido por el complejo supresor tumoral del VHL y, por tanto, no sufre la ubiquitinización. Este hecho le permite al HIF- $\alpha$ permanecer en citoplasma sin degradarse durante más tiempo, estabilizándose. Una vez estabilizado, el HIF- $\alpha$ se transloca al interior del núcleo donde se une con su homólogo, el HIF- $\beta$, que se encuentra siempre constitutivamente activado independientemente de la concentración de oxígeno. La unión del HIF- $\alpha$ 
con el HIF- $\beta$ forma el heterodímero HIF $\alpha \beta$ que actúa como factor de transcripción de los distintos genes implicados en la angiogénesis y en la proliferación celular. El heterodímero $\mathrm{HIF} \alpha \beta$ se une a su vez a otros cofactores de transcripción como el CBP/p300 antes comentado que forman un complejo proteico encargado de la transcripción de los genes inducibles por la hipoxia; el gen del factor de crecimiento vascular endotelial
$(\mathrm{VEGF})^{80}$ ), el gen del receptor del factor de crecimiento epidérmico (EGFR), el factor de crecimiento derivado de plaquetas (PDGFR), transportadores de glucosa como el GLUT-1, el gen del factor de crecimiento transformante- $\alpha$ (TGF- $\alpha$, que a su vez es el ligando del EGFR por lo que forma un circuito de retroalimentación de la proliferación celular), el gen del factor de crecimiento de los fibroblastos (FGF) y la eritropoyetina ${ }^{81}$.

Muchos de estos genes se encuentran implicados en la angiogénesis, supervivencia celular, regulación del $\mathrm{pH} y$ del metabolismo de la célula ${ }^{6}$ (Fig. 4).

Los factores de crecimiento originados a partir de la sobreexpresión de los distintos genes relacionados con la hipoxia van a estimular a sus respectivos receptores que se localizan en la membrana plasmática tanto de los vasos adyacentes (células endoteliales, pericitos, fibroblastos) favoreciendo la angiogénesis, como en la propia membrana de la célula renal que cuenta con potencial para convertirse en tumoral (Fig. 5). Al unirse y activar a los distintos receptores, se genera una cascada de señalización intracelular que deriva en la activación de otros genes relacionados con la pérdida del control de la proliferación celular y la evasión de la apoptosis. Las distintas vías que sigue a nivel intracelular este proceso de activación son básicamente 3 distintas; la vía del fosfatidilinositol-3 fosfato-kinasa (PI3K), la vía del AKT-mammalian target of rapamycin (AKT-mTOR) y la vía de Ras/ Raf/MAP-kinasa ${ }^{81}$.

En tejidos renales normales no se detecta expresión de HIF- $\alpha$, 


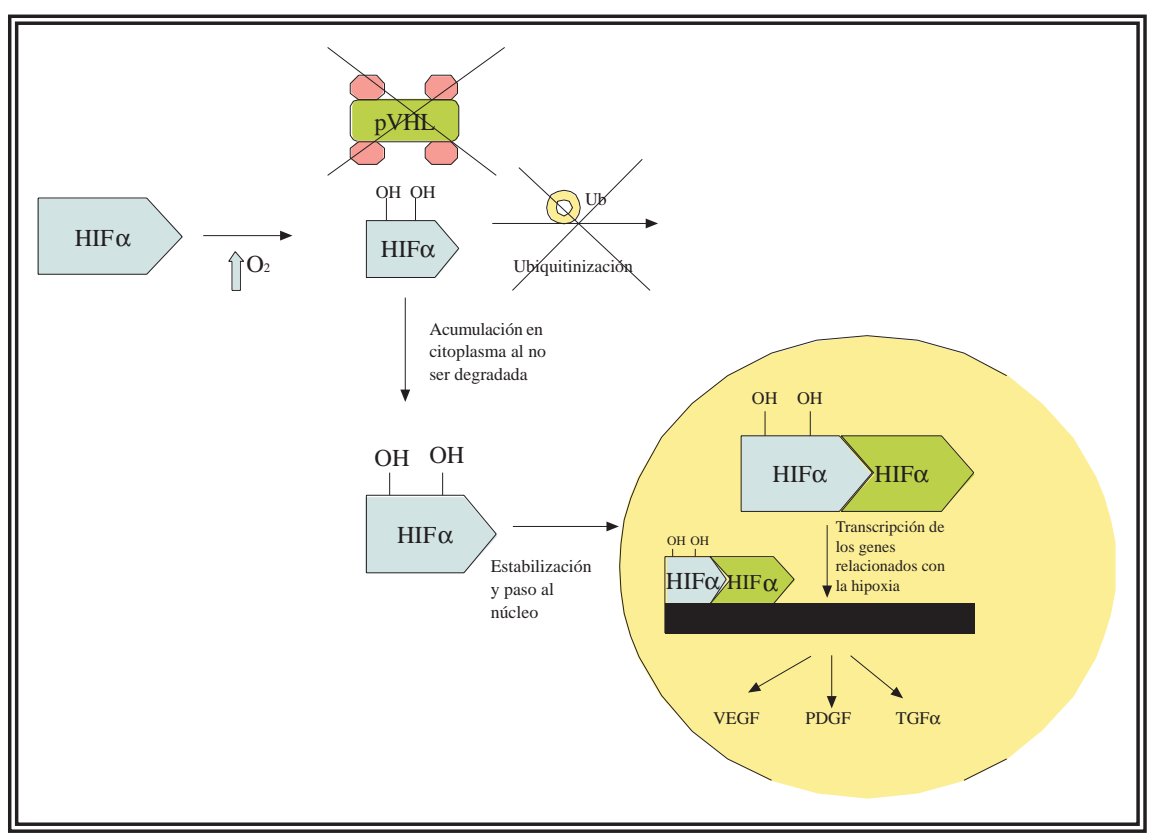

FIGURA 5. Proceso de transcripción de genes relacionados con la hipoxia en condiciones de normoxia pero con deficiencia en la función del complejo proteico supresor tumoral del VHL como tiene lugar en los casos del síndrome de von Hippel-Lindau o CCR de células claras esporádicos asociados a mutación en VHL.

sin embargo, en los tejidos tumorales se evidencia una alta expresión de este factor de transcripción $^{65}$. En tres series distintas ${ }^{82-84}$, se ha evidenciado una alta expresión de HIF- $\alpha$ con independencia del estado mutacional de VHL y una expresión igual o mayor de HIF- $\alpha$ en los tumores que presentaban mutación en el VHL. En los CCR no-células claras en los que no se evidenciaron mutación en el VHL se observó que la expresión de HIF- $\alpha$ fue baja (sólo se observó en 6 de 25 tumores examinados).

La sobreexpresión de VEGF en carcinoma renal de células claras es casi universal. Las diferencias observadas entre autores posiblemente se deban a que la determinación del mismo se realiza mejor en tejido fresco (81-100\% de positividades $)^{84-86}$ que parafinado $(29-46 \%)^{87,88}$. Un grupo japonés ${ }^{84}$ evaluó la relación que existía entre la presencia de mutaciones en VHL, la expresión de HIF- $\alpha$ y la producción de VEGF en tejido sano y tumoral renal de distintos pacientes. La tasa de producción de VEGF entre el tejido tumoral respecto al tejido renal sano fue significativamente mayor en los pacientes con mutación en el gen del VHL respecto a los pacientes con tumores que no tenían dicha mutación
(197,6 vs. $33 ; \mathrm{P}<0.00001)$ y del mismo modo en los pacientes que presentaban sobreexpresión de HIF- $\alpha$ respecto a los que no lo sobreexpresaban $(204,7$ vs 30,$3 ; \mathrm{P}<0.0001)$.

\section{CONCLUSIONES}

La mutación en la línea germinal del gen VHL parece un evento precoz y necesario en el desarrollo del carcinoma renal de células claras. Como consecuencia de la inactivación de la función normal de la proteína del gen VHL se desencadena la sobreexpresión de diferentes factores de crecimiento cuya consecuencia es la inmortalización celular por medio de un mayor aporte de nutrientes a través de mayor permeabilidad vascular y vascularización, inhibición de apoptosis y liberación de factores de crecimiento autocrinos.

El desarrollo del conocimiento de las vías moleculares implicadas en la patogénesis tumoral, especialmente en el carcinoma de células claras, ha permitido el desarrollo de fármacos diseñados para bloquear de forma muy específica determinadas rutas de señalización. Distintos nuevos fármacos que actúan sobre diferentes niveles de las vías de señalización, tales como bevacizumab, sunitinib, sorafenib o temsirolimus han logrado demostrar un aumento tanto en la tasa de respuestas, como en la supervivencia libre de progresión e, incluso, en la supervivencia global respecto al tratamiento clásico empleado en los CCR basado en inmunoterapia. Del mismo modo, también se están investigando tratamientos basados en inhibidores del EGFR tales como erlotinib o gefitinib.

El gran avance en el conocimiento del mecanismo de patogénesis del gen del VHL y el factor de transcripción HIF ha permitido el desarrollo de nuevos fármacos para el tratamiento del CCR; sin embargo aún estamos lejos de objetivos como los de curación o cronificación prolongada por lo que se sigue investigando en otras moléculas que 
sean capaces de inhibir el propio HIF o que puedan bloquear la transcripción en el núcleo de los genes implicados en la angiogénesis, quizá incluso actuando antes de que el fenómeno de carcinogénesis o segundo insulto necesario para el evento final de crecimiento tumoral ocurra.

\section{REFERENCIAS}

1. Schoffski P, Dumez H, Clement P,Hoeben A, Prenen H, Wolter P, et al. Emerging role of tyrosine kinase inhibitors in the treatment of advanced renal cell cancer: a review. Ann Oncol 2006;17(8):1185-1196.

2. Ferlay J, Bray F, Pisani P, Parkin DM. GLOBOCAN 2002: Cancer Incidence, Mortality and Prevalence Worldwide IARC CancerBase No. 5. version 2.0, IARCPress, Lyon, 2004. Available at http://www-dep.iarc.fr/.

3. Lam JS, Leppert JT, Belldegrun AS, Figlin RA. Novel approaches in the therapy of metastatic renal cell carcinoma. World J Urol. 2005;23(3):202-212.

4. Yagoda A, Petrylak D, Thompson S. Cytotoxic chemotherapy for advanced renal cell carcinoma. Urol Clin North Am. 1993;20(2):303-321.

5. Motzer RJ, Bander NH, Nanus DM. Renal-cell carcinoma. N Engl J Med. 1996;335(12):865-875.

6. Patel PH, Chaganti RSK, Motzer RJ. Targeted therapy for metastatic renal cell carcinoma. Brit $J$ Cancer. 2006;94(5):614-619.

7. Hahn WC, Weinberg RA. Rules for making human tumor cells. N Engl J Med. 2002;347(20):1593-1603.

8. Latif F, Tory K, Gnarra J, Yao M, Duh FM, Orcutt ML, et al. Identification of the von Hippel-Lindau disease tumor suppressor gene. Science. 1993;260(5112):1317-1320.

9. Haase VH. The VHL/HIF oxygen-sensing pathway and its relevance to kidney disease. Kidney Int. 2006;69(8):13021307.

10. Collins ET. Intra-ocular growths (two cases, brother and sister, with peculiar vascular new growth, probably retinal, affecting both eyes). Trans Ophthalmol Soc UK. 1894;14: 141-149.

11. Lindau A. Zur Frage der Angiomatosis Retinae und Ihrer Hirncomplikation. Acta Ophthalmol 1927;4:193-226.

12. von Hippel E. Ueber eine sehr seltene Erkrankung der Nethaut. Graefe Arch Ophthalmol 1904;59:83-106.

13. Kondo K, Kaelin WG. The von Hippel-Lindau tumor suppressor gene. Exper Cell Res. 2001;264(1):117-125.

14. McKusick VA. Mendelian Inheritance in Man. Johns Hopkins Univ. Press, Baltimore and London. 1992.

15. Maher ER, Kaelin WG. Von Hippel-Lindau disease. Medicine 1997;76(6):381-391.

16. Maher ER, Yates JR, Harries R, Benjamin C, Harris R, Moore AT, et al. Clinical features and natural history of von Hippel-Lindau disease. Q J Med. 1990;77(283):1151-1158.

17. Kopper L, Timar J. Genomics of renal cell cancer-Does it provide breakthrough? Pathol Oncol Res. 2006;12(1):5-11.

18. Pavlovich CP, Walther MM, Eyler RA, Hewitt SM, Zbar B, Linehan WM, et al. Renal tumors in the Birt-Hogg-Dube syndrome. Am J Surg Pathol. 2002;26(12):1542-1551.

19. Zbar B, Alvord WG, Glenn G, Turner M, Pavlovich CP, Schmidt L, et al. Risk of renal and colonic neoplasms and spontaneous pneumothorax in the Birt Hogg Dube syndrome. Cancer Epidemiol Biomarkers Prev. 2002;11(4): 393-402.
20. Nickerson ML, Warren MB, Toro JR, Matrosova V, Glenn $\mathrm{G}$, Turner ML, et al. Mutations in a novel gene lead to kidney tumors, lung wall defects, and benign tumors of the hair follicle in patients with Birt-Hogg-Dube syndrome. Cancer Cell 2002;2(2):157-163.

21. Da Silva NF, Gentle D, Hesson LB, Morton DG, Latif F, Maher ER. Analysis of the Birt Hogg Dube tumor suppressor gene in sporadic renal cell carcinoma and colorectal cancer. J Med Genet 2003;40(11):820-824.

22. Khoo SK, Kahnoski K, Sugimura J, Petillo D, Chen J, Shockley $\mathrm{K}$, et al. Inactivation of BHD in sporadic renal tumors. Cancer Res 2003;63(15):4583-4587.

23. Cohen HT, McGovern FJ. Renal-Cell Carcinoma. N Engl J Med 2005;353(23):2477-2490.

24. Launonen V, Vierimaa O, Kiuru M, Isola J, Roth S, Pukala E, et al. Inherited susceptibility to uterine leymiomas and renal cell cancer. Proc Natl Acad Sci USA 2001;98(6):3387-3394.

25. Tomlinson IP, Alam NA, Rowan AJ, Barclay E, Jaeger EE, Kelsell D, et al. Germline mutations in FH predispose to dominantly inherited uterine fibroids, skin leymiomata and papillary renal cell cancer. Nat Genet 2002;30(4):406-413.

26. Toro JR, Nickerson ML, Wei MH, Warren MB, Glenn GM, Turner ML, et al. Mutations in the fumarate hydratase gene cause hereditary leyomiomatosis and renal cell cancer in families in North America. Am J Hum Genet 2003; 73(1):95-104.

27. Schmidt L, Duh FM, Chen F, Kishida T, Glenn G, Choyke $\mathrm{P}$, et al. Germline and somatic mutations in the tyrosine kinase domine of the MET proto-oncogene in papillary renal carcinomas. Nat genet 1997;16(1):68-74.

28. Olivero M, Valente G, Bardelli A, Longati P, Ferrero N, Cracco $\mathrm{C}$, et al. Novel mutation in the ATP-bindinf site of the MET oncogene tyrosine kinase in a HPRCC family. Int J Cancer 1999:82(5):640-648.

29. Schmidt LS, Nickerson ML, Angeloni D, Glenn GM, Walther MM, Albert PS, et al. Early onset hereditary papillary renal carcinoma: germline missense mutations in the tyrosine kinase domain of the met proto-oncogene. J Urol 2004;172(4 pt 1):1256-6.

30. Linehan WM, Vasselli, Srinivasan R, Walther MM, Merino M, Choyke P, et al. Genetic basis of cancer of the kidney: disease specific approaches to therapy. Clin Cancer Res 2004;10(18 pt 2):6282-89.

31. Pavlovich CP, Schmidt LS. Searching for the hereditary causes of renal cell carcinoma. Nat Rev Cancer 2004; 4(5):381-393.

32. Richard S, Lidereau R, Giraud S. The growing family of hereditary renal cell carcinoma. Nephrol Dial Transplant 2004;19(12):2954-58.

33. Seizinger BR, Rouleau GA, Ozelius LJ, Lane AH, Farmer GE, Lamiell JM, et al. Von Hippel Lindau disease maps to the region of chromosome 3 associated with renal cell carcinoma. Nature 1988;332(6161):268-269.

34. Latif F, Tory K, Gnarra J, Yao M, Duh FM, Orcutt ML, et al. Identification of the von Hippel Lindau tumor supressor gene. Science 1993;260(5112):1317-1320.

35. Renbaum P, Duh FM, Latif F, Zbar B, Lerman MI, Kuzmin I. Isolation and characterization of the full-length 3' unstranslated region of the human von Hippel Lindau suppressor gene. Hum Genet 1996;98(6):666-671.

36. Kuzmin I, Duh FM, Latif F, Geil L, Zbar B, Lerman ML. Identification of the promoter of the human von Hippel Lindau disease tumor supressor gene. Oncogene 1995;10 (11):2185-2194. 
37. Adryan B, Decker HJ, Papas TS, Hsu T. Tracheal development and the von Hippel Lindau tumor suppressor homo$\log$ in Drosophila. Oncogene 2000;19(24):2803-2811.

38. Gao J, Naglich J, Laidlaw J, Whaley JM, Seizinger BR, Kley $\mathrm{N}$. Cloning and charazterization of a mouse gene with homology to the human von Hippel Lindau disease tumor suppressor gene: Implications for the potential organization of the human von Hippel Lindau disease gene. Cancer Res 1995;55(4):743-747.

39. Duan DR, Humphrey JS, Chen D, Weng Y, Sukegawa J, Lee S, et al. Characterization of the VHL tumor supressor gene product: localization, complex formation, and the effect of natural inactivating mutations. Proc Natl Acad Sci USA 1995;92(14):6495-6499.

40. Woodward E, Buchberger A, Clifford SC, Hurst LD, Affara NA, Maher ER. Comparative sequence anaylsis of the VHL tumor suppressor gene. Genomics 2000;65(3):253-265.

41. Iliopoulos O, Kibel A, Gray S, Kaelin WG. Tumor supression by the human von Hippel Lindau product. Nature Med 1995;1(8):822-826.

42. Iliopoulos O, Ohh M, Kaelin W. pVHL19 is a biologically active product of the von Hippel Lindau gene product. Proc Natl Acad Sci USA 1998;95(20):11661-11666.

43. Schoenfeld A, Davidowitz E, Burk R. A second major native von Hippel Lindau gene product, initiated from an internal translation start site, functions as a tumor supressor. Proc Natl Acad Sci USA 1998;95(15):8817-8822.

44. Blankenship C, Naglich J, Whaley J, Seizinger B, Kley N. Alternate choice of initiation codon produces a biologically active product of the von Hippel Lindau gene with tumor suppressor activity. Oncogene 1999;18(8):1529-1535.

45. Lee S, Chen D, Humphrey JS, Gnarra JR, Linehan WM, Klausner RD. Nuclear/cytoplasmic localization of the von Hippel Lindau tumor supressor gene product is determined by cell density. Proc Natl Acad Sci USA 1996;93(5): 1770-1775.

46. Duan Dr, Pause A, Burgess W, Aso T, Chen DY, Garrett KP, et al. Inhibition of transcriptional elongation by the VHL tumor suppression protein. Science 1995;269(5229):1402-1406.

47. Kibel A, Iliopoulos O, DeCaprio JA, Kaelin WG. Binding of the von Hippel Lindau tumor suppressor protein to elongin B and C. Science 1995;269(5229):1444-1446.

48. Aso T, Lane W, Conaway JW, Conaway RC. Elongin (SIII): a multisubunit regulator of elongation by RNA polymerase II. Science 1995;269(5229): 1439-1443.

49. Ohh M, Takagi Y, Aso T, Stebbins CE, Pavletich NP, Zbar $\mathrm{B}$, et al. Synthetic peptides define critical contracts between elongin $\mathrm{C}$, elongin $\mathrm{B}$, and the von Hippel Lindau protein. J Clin Invest 1999;104(11):1583-1591.

50. Stebbins C, Kaelin W, Pavletich NP. Structure of the VHLElongin C-Elongin B complex: implications for VHL tumor supression function. Science 1999;284(5413):455-461.

51. Kamura T, Sato S, Haque D, Liu L, Kaelin WG, Conaway $\mathrm{RC}$, et al. The elongin $\mathrm{BC}$ complex interacts with the conserved SOCS-box motif present in members of the SOCS, ras, WD-40 repeat, and ankyrin repeat families. Genes Dev 1998; 12(24):3872-3881.

52. Lonergan KM, Iliopoulos O, Ohh M, Kamura T, Conaway Rc, Conaway JW, et al. Regulation of hypoxia-inducible mRNAs by the von Hippel-Lindau protein requires binding to complexes containing Elongins B/C and Cul2. Mol Cell Biol 1998; 18(2):732-741.

53. Deshaies R. SCF and cullin/ring H2-based ubiquitin ligases. Annu Rev Cell Dev Biol 1999;15:435-467.
54. Kamura T, Koepp DM, Conrad M, Skowyra D, Moreland $\mathrm{RJ}$, Iliopoulos $\mathrm{O}$, et al. Rbx1, a component of the VHL tumor supressor complex and SCF ubiquitin ligase. Science 1999;284(5414):657-661.

55. Kamura T, Conrad M, Yan Q, Conaway RC, Conaway JW. The Rbx1 subunit of SCF and VHL E3 ubiquitin ligase activates Rub1 modification of cullins Cdc53 and Cul2. Genes Dev 1999; 13(22):2928-2933.

56. Skowyra D, Koepp DM, Kamura T, Conrad MN, Conaway Rc, Conaway JW, et al. Reconstitution of G1 cyclin ubiquitination with complexes containing SCFGrr1 and Rbx1. Science 1999;284(5414):662-665.

57. Ohta T, Michel JJ, Schottelius AJ, Xiong Y. ROC1, a homo$\log$ of APC 11, represents a family of cullin partners with an associated ubiquitin ligase activity. Mol Cell 1999;3(4): 535-541.

58. Ohh M, Park C, Ivan M, Hoffman MA, Kim TY, Huang LE, et al. Ubiquitination of HIF requires direct binding to the von Hippel Lindau beta domain. Natur Cell Biol 2000;2(7):423-427.

59. Kamura T, Sato S, Iwai K, Czyzyk-Krzeska M, Conaway $\mathrm{RC}$, Conaway JW. Activation of HIF la ubiquitination by a reconstituted von Hippel Lindau tumor supressor complex. Proc Natl Acad Sci USA 2000;97(19):10430-10435.

60. Tanimoto K, Makino Y, Pereira T, Poellinger L. Mechanism of regulation of the hypoxia inducible factor-1-alpha by the von Hippel-Lindau tumor suppressor protein. EMBO J 2000;19(16):4298-4309.

61. Wenger RH. Cellular adaptation to hypoxia: O2-sensing protein hydroxylases, hypoxia-inducible transcriptions factors, and O2-regulated gene expression. FASEB J 2002; 16(10): 1151-1162.

62. Pugh CW, Ratcliffe PJ. Regulation of angiogenesis by hypoxia: role of the HIF system. Nat Med 2003;9(6):677-684.

63. Higgins DF, Biju MP, Akai Y, Wutz A, Johnson RS, Haase VH. Differential roles of hypoxia inducible factor lalpha (HIF-1alpha) and HIF-2alpha in hypoxic gene regulation. Mol Cell Biol 2003;23(2):9361-9374.

64. Knudson AG. Genetics of human cancer. Annu Rev Genet 1986;20:231-251.

65. Rini B, Small SJ. Biology and clinical development of vascular endothelial growth factor-targeted therapy in renal cell carcinoma. J Clin Oncol 2005;23(5):1028-1043.

66. Crossey PA, Foster K, Richards FM, Phipps ME, Latif F, Tory $\mathrm{K}$, et al. Molecular genetics investigations of the mechanism of tumourigenesis in von Hippel-Lindau disease: analysis of allele loss in VHL tumours. Hum Genet 1994;93(1):53-58.

67. Gnarra JR, Tory K, Weng Y, Schmidt L, Wei MH, Li H, et al. Mutations of the VHL tumor suppressor gene in renal cell carcinoma. Nat Genet 1994;7(1):85-90.

68. Shuin T, Kondo K, Torigoe S, Kishida T, Kubota Y, Hosaka $\mathrm{M}$, et al. Frequent somatic mutations and loss of heterozygosity of the von Hippel-Lindau tumor suppressor gene in primary human renal cell carcinomas. Cancer Res 1994;54(11):2852-2855.

69. Kondo K, Yao M, Yoshida M, Kishida T, Shuin T, Miura T, et al. Comprehensive mutational analysis of the VHL gene in sporadic renal cell carcinoma: relationship to clinicopathological parameters. Genes Chromosomes Cancer 2002; 34(1):58-68

70. Brauch H, Weirich G, Brieger J, Glavac D, Rodl H, Eichinger $\mathrm{M}$, et al. VHL alterations in human clear cell renal cell carcinoma: association with advanced tumor stage and a novel hot spot mutation. Cancer Res 2000;60(7):1942-48. 
71. Gallou C, Joly D, Mejean A, Staroz F, Martin N, Tarlet G, et al. Mutations of the VHL in sporadic renal cell carcinoma: definition of a risk fator for VHL patients to develop a RCC. Hum Mutat 1999;13(6):464-475.

72. Schrami P, Struckmann K, Hatz F, Sonnet S, Kully C, Gasser T, et al. VHL mutations and their correlation with tumor cell proliferation, microvessel density, and patient prognosis in clear cell renal cell carcinoma. J Pathol 2002; 196(2): 186-193.

73. Herman JG, Latif F, Weng Y, Lerman MI, Zbar B, Liu S, et al. Silencing of the VHL tumor suppressor gene by DNA methylation in renal carcinoma. Proc Natl Acad Sci USA 1994;91(21):9700-9704.

74. Clifford SC, Prowse AH, Affara NA, Buys CH, Maher ER. Inactivation of the von Hippel Lindau (VHL) tumor suppressor gene and allelic losses at chromosome arm $3 p$ in primary renal cell carcinoma: evidence for a VHL-independent pathway in clear renal cell renal tumourigenesis. Genes Chromosomes Cancer 1998;22(3):200-209.

75. Foster K, Prowse A, van der Berg A, Fleming S, Hulsbeek MM, Crosey PA, et al. Somatic mutations of the von Hippel Lindau disease tumor suppressor gene in non-familial clear cell renal carcinoma. Hum Mol Genet 1994;3(12): 2169-2173.

76. Ljungberg B, Alamdari FI, Stenling R, Roos G. Prognostic significance of the Heidelberg classification of renal cell carcinoma. Eur Urol 1999;36(6):565-569.

77. Cheville JC, Lohse CM, Zincke H, Weaver AL, Blute ML, et al. Comparisons of outcome and prognostic features among histologic subtypes of renal cell carcinoma. Am J Surg pathol 2003;27(5):612-624.

78. Wang Gl, Semenza GL. General involvement of hypoxia inducible factor 1 in transcriptional response to hypoxia. Proc Natl Acad Sci USA 1993;90(9):4304-4308.

79. Hon WC, Wilson MI, Harlos K, Claridge TD, Schofield CJ, Pugh CW, et al. Structural.basis for the recognition of hydroxiproline in HIF-1alpha by pVHL. Nature 2002;417 (6892):975-978.

80. Shweiki D, itin A, Soffer D, Keshet E. Vascular endothelial growth factor induced by hypoxia may mediate hypoxiainitiated angiogenesis. Nature 1992;359(6398):843-845.

81. Bardos JI, Ashcroft M. Hypoxia-inducible factor-1 and oncogenic signalling. Bioessays 2004;26(3):262-269.
82. Wiesener MS, Munchenhagen PM, Berger I, Morgan NV, Roigas J, Schwiertz A, et al. Constitutive activation of hypoxia-inducible genes related to overexpression of hypoxia inducible factor 1-alpha in clear cell renal carcinomas. Cancer Res 2001;61(13):5215-5222.

83. Turner KJ, Moore JW, Jones A, Taylor CF, CuthbertHeavens D, Han C, et al. Expression of hypoxia inducible factors in human renal cancer: relationship to angiogenesis and to von Hippel Lindau gene mutation. Cancer Res 2002;62(10):2957-2961.

84. Na X, Wu G, Ryan CK, Schoen SR, di'Santagnese PA, Messing EM. Overproduction of vascular endothelial growth factor related to von Hippel Lindau tumor supressor gene mutations and hypoxia inducible factor 1-alpha expression in renal cell carcinomas. J Urol 2003;170(2 pt 1):588-592.

85. Lee JS, Kim HS, Jung JJ, Lee MC, Park CS. Expression of vascular endothelial growth factor in renal cell carcinoma and the relation to angiogenesis and p53 protein expression. J Surg Oncol 2001;85(3):55-60.

86. Nicol D, Hii SI, Walsh M, Teh B, Thmpson L, Kennett C, et al. Vascular endothelial growth factor expression is increased in renal cell carcinoma. J Urol 1997;157(4):14821486.

87. Paradis V, Lagha NB, Zeimoura L, Blanchet P, Eschwege P, $\mathrm{Ba} \mathrm{N}$, et al. Expression of vascular endothelial growth factor in renal cell carcinomas. Virchows Arch 2000;436(4): 351-356.

88. Song KH, Song J, Jeong GB, Blanchet P, Eschwege P, Ba $\mathrm{N}$ et al. Vascular endothelial growth factor- its relation with neovascularization and their significance as prognostic factors in renal cell carcinoma. Yonsei Med J 2001; 42:539-546.

Correspondencia autor: Dr. E. Grande Pulido Departamento Médico de Pfizer. Avda. de Europa, $20 \mathrm{~B}$. 28050 Alcobendas. Madrid.

E-mail autor: enrique.grandepulido@pfizer.com

Información artículo: Revisión - Cáncer renal

Trabajo recibido: diciembre 2006

Trabajo aceptado: febrero 2007 